\title{
Competencias lingüísticas de docentes de párvulos. Un análisis del discurso conversacional de profesionales de la Junta Nacional de Jardines Infantiles
}

\author{
Linguistic Competence of Preschool Teachers. An Analysis of Conversational Discourse \\ in Professionals from the Chilean National Board of Early Education \\ (Junta Nacional de Jardines Infantiles)
}

\author{
Sandra Ruperta Pérez Lisboa ${ }^{1}$ \\ Universidad de Playa Ancha \\ San Felipe, Chile \\ sandra.perez@upla.cl
}

Recibido 02 de junio de 2013 • Corregido 27 de setiembre de 2013 • Aceptado 01 de octubre de 2013

Resumen. Las competencias lingüísticas de docentes de párvulos son un referente continuo en el desarrollo del lenguaje de niñas y niños. Esto, porque son un modelo, debido a que utilizan constantemente la comunicación oral para trabajar, jugar o dar instrucciones. En relación con esta premisa, esta investigación tiene por objetivo analizar las competencias lingüísticas de un grupo de educadoras de párvulos del nivel transición menor. Con base en la observación de docentes que trabajan en la Junta Nacional de Jardines Infantiles - de la zona poniente de la provincia de Santiago-, se realizó un estudio relativo al discurso conversacional de las profesionales. Se plantea que la posesión de mayores competencias lingüísticas, por parte de educadores, favorece el desarrollo del lenguaje oral de los párvulos.

Palabras claves. Competencias lingüísticas, educadoras de párvulos, discurso conversacional, Junta Nacional de Jardines Infantiles, desarrollo del lenguaje.

Abstract. The linguistic competence of preschool teachers are an ongoing referent in the linguistic development of preschoolers since teachers are models for them, because they constantly use oral communication to work, play, and give instructions. Regarding this premise, this paper is aimed at analyzing the linguistic competence of a group of preschool teachers at the lower transition level. Based on the observation of teachers working at the Chilean National Board of Early Education (Junta Nacional de Jardines Infantiles) in the western area of the province of Santiago, a study was conducted regarding teachers' conversational discourse. It is proposed that higher language skills in teachers promote the oral language development of young children.

Keywords. Linguistic competences, preschool teachers, conversational discourse, Chilean National Board of Early Education (Junta Nacional de Jardines Infantiles), language development.

Educadora de Párvulos, Pontificia Universidad Católica de Chile; Magíster en Pedagogía y Gestión Universitaria, Universidad Metropolitana de Ciencias de la Educación. Docente del Departamento Disciplinario de Educación Parvularia, Universidad de Playa Ancha. 
Las personas educadoras cumplen con el rol de facilitadoras en el proceso de formación del educando. Siguiendo a Gutiérrez y Montes (2004), se concibe el aprendizaje como la reconstrucción de los esquemas de conocimientos del sujeto, por medio de las experiencias que este tiene con los objetos -interactividad-y con las personas -intersubjetividad- en hechos de interacción que sean significativos de acuerdo con su nivel de desarrollo y los contextos sociales que le dan sentido.

Para que un niño construya saberes, debe saber cómo hacer y cómo emprender. Para esto es indispensable que sus aprendizajes se realicen a través de las experiencias directas en situaciones de la vida diaria, en relación con el mundo que lo rodea. ¿Cómo aprendemos y conocemos el mundo? Lo hacemos por medio del lenguaje, ya que este desempeña una doble función: constituye un modo de comunicación y una forma de representar el mundo que se comunica.

El aprendizaje de la lengua materna es un proceso natural de todas las personas, la función del educador y la educadora es realizar una intervención intencionada para fortalecerla, en su rol de persona mediadora eficiente. Este rol se apoya fuertemente en las contribuciones de Feuerstein (1999), quien comprende a la persona como un sistema abierto y modificable, donde la inteligencia no es un valor invariable, sino que constituye un proceso de autorregulación dinámica, sensible a la intervención de un mediador eficiente. Esto implica proporcionar a los niños y niñas un ambiente afectivo que les permita expresarse con confianza, para poder ordenar, enmarcar y sistematizar los estímulos. De esta manera, los párvulos pueden focalizar su atención para favorecer sus descubrimientos frente al lenguaje.

La comunicación que se establece entre los párvulos y sus educadores se da constantemente por medio del discurso conversacional en las experiencias de aprendizajes, las cuales se planifican por medio de un eje centralizador. Esta instancia pedagógica es una de las responsables de la construcción del conocimiento en el aula. Como la educadora y el educador son los mediadores que favorecen este aprendizaje, es de interés conocer si poseen las competencias lingüísticas apropiadas para establecer un adecuado discurso conversacional con los niños y niñas. Los ejes centrales del proceso de formación cruzan su saber, saber hacer y saber ser.

El propósito de este estudio es dar a conocer las competencias lingüísticas profesionales que poseen las educadoras de párvulos de la Junta Nacional de Jardines Infantiles (en adelante JUNJ) que trabajan en la zona poniente de la Región Metropolitana, en las comunas de Cerrillos, Cerro Navia, Lo Prado, Maipú, Pudahuel y Renca; con el objetivo de potenciar el desarrollo del lenguaje oral en los niños y niñas de cuatro a cinco años de edad.

Esta investigación se orienta con las siguientes preguntas: ¿Cuáles son las competencias lingüísticas que deben tener las personas educadoras de párvulos para lograr un discurso conversacional con los niños y niñas? ¿Cuáles son los niveles de dominio de las competencias lingüísticas de las personas educadoras de párvulos en el discurso conversacional? ¿Cuáles son las dificultades este grupo de profesionales en este discurso? ¿Cómo se produce el discurso conversacional entre docente y educando? ¿Cómo son los comportamientos lingüísticos en el 
lenguaje docente? Se realizan estas preguntas para reflexionar sobre los comportamientos del lenguaje utilizado en el discurso conversacional por las educadoras.

\section{Conceptualización}

El lenguaje oral es la base de la relación diaria que niños y niñas tienen en el jardín infantil, lo que implica el ejercicio de la palabra, la escucha atenta y la percepción de los mensajes. Para ello es indispensable proveerles una variedad de intercambios orales: conversaciones, narraciones, discursos, debates, entre otros, que les permitirá favorecer la reflexión sobre las características de este tipo de comunicación. Los adultos y adultas responsables, principalmente las personas educadoras de párvulos, deben ser modelos para desarrollar y enriquecer el lenguaje.

\section{El lenguaje}

Primeramente se definirá lenguaje desde una perspectiva neurobiológica. De acuerdo con Dale (2003), el lenguaje "...es una función cortical superior (necesita orgánicamente de la corteza cerebral) que a su vez se coordina con múltiples otras [sic] habilidades" (p. 8). Por esto es fundamental que su evolución sea adecuada, ya que se relaciona estrechamente con la percepción, la memoria, el pensamiento, entre otros.

Desde una perspectiva psicopedagógica, se puede explicar como: “Un sistema compuesto por unidades (signos lingüísticos) que mantienen una organización interna de carácter formal; su uso permite formas singulares de relación y acción sobre el medio social que se materializa en formas concretas de conducta" (Acosta y Moreno, 1999, p. 2). En este contexto, el lenguaje es de origen social, ya que comienza a partir de la interacción con los otros. La lengua materna se desarrolla cuando el niño tiene una comunicación intencional con su madre u otro adulto. Esta comunicación le proporciona al niño las competencias lingüísticas, comunicativas y pragmáticas que se van adquiriendo durante su vida. Según Maturana, citado en Echeverría (1977), cada persona puede hacer lo que biológicamente le está permitido, pero no se puede olvidar que para desarrollar esta habilidad (a pesar de necesitar biológicamente hablando del aparato de fonación y a su vez este del sistema nervioso central) requiere de “...la interacción social entre los seres humanos..." (p. 50).

\section{Teoría del lenguaje interaccionista}

Esta teoría, propuesta por el psicólogo Bruner (1998), establece un puente entre las nuevas tendencias influenciadas por la psicología social, el constructivismo y el enfoque pragmático de las funciones del lenguaje. Para este autor lo que es innato en los seres humanos es la actividad motriz, la que luego es perceptiva para llegar a las primeras operaciones y siempre de acuerdo con unas reglas codificadas que se van estructurando y flexibilizando en la interacción y la experiencia. 
URL: http://www.una.ac.cr/educare

CORREO: educare@una.cr

Según esta teoría, el desarrollo de la niñez está determinado por diferentes estímulos y agentes culturales como sus padres, madres, maestros, maestras, amigos, amigas y demás personas que son parte de su comunidad y del mundo que la rodea. Esto le proporciona una serie de contactos y experiencias que le permiten poseer conocimientos previos, los que están en constante transformación. Entonces, el niño descubre el mundo por medio de sus acciones, más tarde lo hace a través del lenguaje y, por último, tanto la acción como la imagen son traducidas en lenguaje.

\section{Discurso conversacional}

Se entiende por discurso "... una unidad semántica pragmática constituida por una secuencia de oraciones relacionadas coherentemente en torno a un tema y emitida con una determinada intención comunicativa en una situación concreta" (Pavez, Coloma, González, Palma y Reinoso, 1999, pp. 17-32).

El discurso ha sido enfocado desde diferentes perspectivas teóricas, porque es una entidad muy compleja. Algunos autores señalan que el discurso es una unidad lingüística que se emite en una situación comunicativa particular con una intención determinada y expresa un mundo real o posible. Un adecuado manejo del discurso necesita que el emisor pueda transmitir efectivamente su intención comunicativa. Para eso necesita de habilidades sociales que le permitan adaptarse a distintos receptores (pares, subordinados, conocidos, desconocidos) en diferentes entornos (oficina, casa, calle, sala de clases, entre otros espacios). El manejo adecuado del discurso permite que la intención comunicativa sea eficaz, es decir, que el propósito buscado por el emisor se logre.

La conversación es una comunicación en la que participan dos o más personas para trasmitir y desarrollar diferentes temas. Según Martínez, se define como “...la forma básica de interacción. Incluso es la matriz a partir de la cual se desarrolla el lenguaje, la cognición y la afectividad" (1999, p. 1). Para este estudio se aborda la comunicación desde una perspectiva pragmática comunicativa, teniendo en cuenta su naturaleza interactiva, los elementos lingüísticos y no lingüísticos que participan en un discurso.

El discurso conversacional se realiza en forma conjunta, colaborativa y en constante transformación. Esto implica varios factores de diversa naturaleza: sociales, lingüísticos, culturales y cognitivos. Para analizar un discurso conversacional se deben considerar los siguientes aspectos:

1. Estructura: el discurso conversacional consiste “... en una serie de en unciados relacionados coordinadamente entre si" (Martínez, 1999, p. 1). Los enunciados se organizan por las reglas de conexión de interacciones y acciones, las cuales tienen las siguientes características: conectados, representan intenciones y acciones factibles y acciones 
sucesivas en el tiempo, representan acciones que sean consecuencia de otras acciones e interacciones alternantes respecto a la alternancia, por último, representan interacciones unilaterales o bilaterales en lo concerniente a los participantes. La estructura se puede dividir en: inicio, desarrollo -mediante manejo de turno-y cierre.

a) Inicio: es la invitación que debe hacer alguna de las personas para que haya una conversación. La forma más frecuente es por medio del saludo.

b) Desarrollo mediante sistema de turno: es una especie de sistema de trasmisión que opera para asegurar la emisión y recepción del mensaje en una conversación. Para que haya un buen manejo de turnos una de las personas debe cumplir el rol de hablante en forma espontánea o cuando la otra le da esa función. Posteriormente, el otro debe asumir la tarea de oyente hasta cuando se le permite o cambie de rol. El sistema de turno provoca que los participantes de la conversación organicen sus acciones de forma sistemática. Cuando no hay organización en los participantes ocurre la sobreposición de turno, la cual se da, frecuentemente, en la finalización de la conversación, en un punto redundante de esta, y cuando los temas de la conversación son poco interesante para el oyente.

c) Cierre: cuando finaliza la conversación -la cual debe tener una señal que determine el cierre- normalmente se da con la despedida.

2. Contenido: como la conversación es colaborativa, el contenido debe ser común para todos los que participan en ella. En este aspecto se evalúa el manejo de tópico, el cual incluye unas series de habilidades específicas como competencias lingüísticas y variables cognitivas y psicolingüística de cada persona.

En un discurso conversacional es importante observar que sea coherente y cohesivo, por eso uno de los factores cognitivos que debe estar presente para la continuidad de la conversación es la generación y acumulación de conocimiento, el cual debe ser conocido por todos los participantes (educadores y niños). Es importante destacar que en un discurso pueden exponerse varios tópicos distintos y que no siempre todos se desarrollan de manera completa. El manejo del tópico posibilita que se desenvuelvan los diferentes contenidos del discurso conversacional. Estos se pueden disponer de dos formas: como resultado de la coherencia de una conversación -donde los hablantes retoman enunciados previos y desarrollan nuevos tópicos a partir de esos enunciados-y cuando una conversación se establece según un tópico central.

3. Modalidad: es el tipo de comunicación que se utiliza en un discurso conversacional. Esta puede ser: 
URL: http://www.una.ac.cr/educare

CORREO: educare@una.cr

a) Verbal: es aquella comunicación que permite trasmitir información. Cuando nos comunicamos compartimos todo tipo de mensajes: emociones, ideas, conceptos, advertencias, necesidades, órdenes, entre otras. Para que esta información llegue al oyente es necesario que el hablante cumpla con ciertas habilidades tales como el uso de la voz, el tono de la voz, el vocabulario conocido, la forma de entregar la información. Estas habilidades le permitirán al oyente interactuar con el hablante.

b) No verbal: son todas aquellas señas o señales relacionadas con situaciones de interacción comunicativa que no se catalogan como palabras escritas o habladas. Se relacionan con el uso de la voz y el cuerpo para complementar el significado del mensaje, e informan acerca del estado de ánimo o la intencionalidad de la persona que habla. Los signos de los sistemas de comunicación no verbal pueden regirse por códigos culturales o reacciones naturales que reforman, de alguna manera, el significado del discurso conversacional. Pueden ser utilizados consciente o inconscientemente, en actos de comunicación ocasionalmente imperceptibles para el emisor, pero no para el receptor. Son heterogenias y se pueden clasificar en dos grupos: las que hacen referencia al cuerpo e incluye al físico, los movimientos (kinestésico), el manejo del espacio, el tacto y los patrones de contacto ocular; y los objetos y artefactos que utilizan las personas, como vestimenta, adornos, etc.

\section{El rol de quien educada párvulos}

El educador de párvulos es quien lidera el proceso de enseñanza y aprendizaje. En su trabajo pedagógico debe dotar de intencionalidad educativa las interacciones con los niños y niñas, y los espacios en donde se desarrollan, para establecer relaciones potenciadoras de aprendizajes.

El documento Bases curriculares de la educación parvularia describen el rol docente de párvulos como: "Formadora y modelo de referencia para las niñas y niños, junto con la familia; diseñadora, implementadora y evaluadora de los currículos, dentro de lo cual su papel de seleccionadora de los procesos de enseñanza y de mediadora de los aprendizaje es crucial" (Ministerio de Educación [MINEDUC], 2001, p. 14). De acuerdo con esto, quien educa párvulos es un agente educativo que media aprendizajes en el niño, a través de una participación oportuna, intencionada, pertinente y significativa, que ofrece al párvulo experiencias educativas valiosas y variadas. La intervención educativa debe ser adecuada al momento de aprendizaje en que esté el niño y la niña, y que tenga sentido para ellos (tanto porque se trata de una experiencia que se relaciona con sus aprendizajes previos, como porque contiene elementos nuevos que le significan un desafío). 
URL: http://www.una.ac.cr/educare CORREO: educare@una.cr

La práctica pedagógica del educador tiene como propósito potenciar al máximo a los niños y niñas en su capacidad de aprender y modificarse, de modo que avancen en su aprendizaje y se desarrollen. Este proceso es una construcción entre los docentes y los niños, en donde el educador -partiendo de las experiencias y motivaciones particulares del párvulodebe hacer que este asuma un papel activo y protagónico en el proceso. Peralta (1996) da las siguientes funciones generales a los educadores de párvulos:

- Diagnosticar características, necesidades e intereses de los párvulos.

- Definir y formular los objetivos a favorecer.

- Planificar y organizar las diferentes estrategias de aprendizaje para los niños.

- Crear un ambiente efectivo, receptivo confiado en función de los párvulos.

- Interactuar con los niños, atendiendo tanto necesidades grupales como personales.

- Realizar todo tipo de actividades tanto aquellas que apuntan a objetivos más estables, como a otros más variables.

- Observar, registrar, medir y evaluar el desarrollo de los niños.

- Coordinar y orientar a los adultos que componen el equipo de trabajo, que interactúa con los niños en el jardín infantil.

- Detectar las normas y prácticas de crianzas tanto familiares como comunitarias que existen.

- Detectar aquellas necesidades, tanto familiares como comunitarias, que inciden más directamente con la educación de los niños.

- Planificar las acciones a desarrollar, según diagnóstico elaborado.

- Realizar las diferentes acciones tendientes a llevar a cabo los objetivos propuestos.

- Evaluar las diferentes acciones emprendidas. (p. 48)

Estas funciones planteadas por la autora son generales, ya que se pueden desglosar según la modalidad curricular por la que se guía el educador en su quehacer pedagógico. Es el personal docente quien conduce el proceso educativo de los niños y las niñas, pero siempre en el marco de un trabajo colectivo al cual aporta y construye en equipo. Además, es el encargado de relevar la presencia de su nivel en la comunidad educativa. El educador de párvulos emplea diversos recursos y escenarios para promover, en los niños y niñas, la curiosidad y el gusto por aprender, preocupándose de revelar oportunidades y experiencias educativas diversas que les ofrezcan diferentes posibilidades de elección y de decisión 
URL: http://www.una.ac.cr/educare

CORREO: educare@una.cr

\section{El lenguaje en las Bases curriculares de la educación parvularia}

En Chile, en el año 1998 se inició la Reforma Curricular en Educación Parvularia. Con la elaboración de las Bases curriculares y su posterior publicación en el año 2001, la reforma curricular proporcionó una mejora en la gestión educativa para el beneficio de todos los niños y niñas residentes en el país. Este documento "busca modificar sustancialmente los modos de trabajos pedagógicos que hoy en día, ... adecuado a las necesidades que actualmente Chile posee, como son desarrollo de las habilidades cognitivas, el lenguaje, la capacidad emprendedora del niño, la capacidad de solución de problemas, y en general el desarrollo de las potencialidades del niño y la niña" (MINEDUC, 2001, p. 7).

En esta definición de educación parvularia, se establece que existe un compromiso ético y profesional del educador y la educadora de párvulos para asumir los procesos de cambios a fin de mejorar las prácticas educativas y lograr una educación de calidad para niños y niñas. Dentro de los componentes estructurales de las Bases curriculares de la educación parvularia, se encuentran los siguientes ámbitos de experiencia para el aprendizaje: formación personal y social, comunicación y relación con el medio natural y cultural. La comunicación es definida como "el proceso central mediante el cual niños y niñas desde los primeros años de vida intercambian y construyen significado con los otros" (MINEDUC, 2001, p. 56). De este ámbito de experiencia para el aprendizaje se desprenden dos núcleos: uno referido al lenguaje verbal y otro al lenguaje artístico.

Para esta investigación solo se definirá el lenguaje verbal como "la capacidad para relacionarse con otros escuchando, recibiendo comprensivamente y produciendo diversos mensajes, mediante el uso progresivo y adecuado del lenguaje verbal y no verbal, en sus expresiones orales y escritas" (MINEDUC, 2001, p. 59). Esto implica avanzar desde los primeros balbuceos a las oraciones, empleándolas para comunicarse según las distintas funciones, en diferentes contextos y con variados interlocutores, utilizando un vocabulario y estructuras lingüísticas adecuadas a su desarrollo e iniciándose, además, en la lectura y escritura. Este núcleo incluye veintiún aprendizajes esperados para el nivel de transición mayor ${ }^{2}$, los que están orientados a favorecer de manera progresiva en los niños y niñas la capacidad de desarrollar competencias lingüísticas, las que les permitirán interactuar con su medio social.

En este núcleo se potencia tanto el lenguaje verbal como el no verbal, estimulando progresivamente el lenguaje escrito. La comunicación se va desarrollando en los niños y niñas a partir de los primeros meses por medio del lenguaje no verbal; gestos y movimientos que manifiestan sus necesidades, expresan sensaciones y sentimientos; para luego, poco a poco, adquirir el lenguaje verbal al poder representar los objetos del medio social y cultural.

En este contexto, las experiencias que se les presentan a los párvulos enriquecen "...las posibilidades para desarrollar la práctica comunicativa, a través del uso progresivo y adecuado

2 El nivel transición menor atiende a los niños y niñas de 4 años a 4 años 11 meses de edad. 
URL: http://www.una.ac.cr/educare CORREO: educare@una.cr

de las diferentes expresiones lingüísticas orales" (MINEDUC, 2001, p. 57), donde los párvulos puedan representar, comprender y expresar el mundo que les rodea para la construcción de aprendizajes.

Quien educada en parvularios debe propiciar, entonces, diferentes experiencias para favorecer el discurso. Siguiendo a Freire (1973), "el diálogo es el encuentro amoroso de los hombres que, mediatizados por el mundo, lo 'pronuncian', esto es, lo transforman y, transformándolo, lo humanizan, para la humanización de todos" (p. 46).

\section{Programa Educativo de la Junta Nacional de Jardines Infantiles (JUNJ)}

La Junta Nacional de Jardines Infantiles es una institución del Estado de Chile, fundada en 1970 por la Ley $N^{\circ} 17.301$, como un estamento autónomo vinculado al Ministerio de Educación y cuyo fin es atender a los niños y niñas del país, en zonas urbanas altamente pobladas y semiurbanas, donde existen habitantes en situación de vulnerabilidad para contribuir a la igualdad de oportunidades y mejorar la calidad de la educación infantil.

Para este propósito, esta institución no utiliza un tipo de modalidad curricular, sus jardines están abiertos para que cada uno opte según lo que la comunidad educativa elija. Pero la mayoría de los establecimientos educativos utilizan el currículo integral que históricamente precede a las otras modalidades existentes.

La comunidad educativa establece el proyecto educativo, esta guía y anticipa el trabajo pedagógico, entregándole identidad, cohesión, dirección e integración. En esta comunidad participan el equipo de aula y la familia, quienes estructuran y coordinan la planificación a largo, mediano y corto plazo con el objetivo de favorecer los aprendizajes significativos y relevantes de los niños y niñas.

Para esta institución, el rol del educador y educadora de párvulos es un factor clave en el proyecto, ejecución y evaluación del currículo, por eso debe liderar la búsqueda de estrategias con el fin que los niños y niñas logren los aprendizajes esperados. Para ello, el educador debe velar para que este ambiente ofrezca valiosas y variadas oportunidades de juego, exploración, manipulación, interacción, elección y reflexión; todo esto, sin olvidar cautelar en todo momento la seguridad y bienestar físico y psicológico que este espacio ofrece a los niños y niñas.

\section{Metodología}

Esta investigación, de tipo descriptivo, se encuadra desde un enfoque cuantitativo, el cual analiza diversos elementos que pueden ser medidos. Este enfoque otorga el carácter científico de la investigación categorizando los fenómenos sociales en variables. 
URL: http://www.una.ac.cr/educare

CORREO: educare@una.cr

\section{Muestra}

La muestra la conforman 16 educadoras (todas mujeres) de párvulos que trabajan en la Junta Nacional de Jardines Infantiles de la zona poniente de la Región Metropolitana, que corresponden a los municipios de Cerrillos, Cerro Navia, Lo Prado, Maipú, Pudahuel y Renca. En la zona poniente hay un total de treinta y seis jardines infantiles de la JUNJl, de los cuales dieciséis de ellos tienen el nivel transición menor.

\section{Instrumento}

Para la producción de la información se utilizó una pauta de observación de la acción pedagógica en el aula de las educadoras de párvulos. La pauta de observación se diseñó como un instrumento para analizar su discurso conversacional con los niños y niñas cuando está realizando ciertas actividades. Dicho instrumento se organizó tomando en cuenta cada uno de los componentes de la estrategia metodológica del discurso conversacional (estructura, contenido y modalidad), como una manera de registrar la comunicación como acción colaborativa. Para mantener objetividad en el estudio, se observó la actividad de todas las educadoras por dos evaluadoras, las cuales -una vez terminada la actividad- aplicaban la pauta. Además se tomó la precaución de grabar la acción pedagógica para evitar errores en el caso de alguna discrepancia.

La pauta de observación tiene treinta y cuatro indicadores, que miden las tres variables por evaluar. Después de cada indicador se presentan dos casilleros, en los cuales las evaluadoras respondieron marcando con una cruz $<<$ Sí $\rangle>$ cuando observaron lo descrito; o de lo contrario, marcaban la opción $<<$ No $>>$.

Antes de ser aplicada a las 16 profesionales participantes de este estudio, la pauta fue validada empíricamente a juicio de expertos en el área del lenguaje y metodología de la investigación. Además, se administró a tres educadoras que se desempeñaban en el nivel transición menor, y que no estaban consideradas en este estudio. Esta validación la realizaron tres expertos de la Escuela de Fonoaudiología de la Facultad de Medicina de la Universidad de Chile. Para ello, se les pidió que fueran respondiendo en la pauta de observación si cada una de las aseveraciones evaluaba lo indicado, marcando con una cruz $<\langle$ Sí $\rangle>0<<$ No $\rangle>$. Después, se contrastaron las respuestas para construir el instrumento final, el cual se les aplicó a los profesionales señalados anteriormente.

\section{Variables analizadas}

A continuación se describen las variables analizadas en este estudio.

a) Estructura: en este tópico se consideran una serie de secuencias de acción que deben estar coordinados entre sí: inicio, desarrollo mediante manejo de turno y cierre. 
b) Contenido: también se le llama manejo del tópico. Este involucra una serie de habilidades específicas que permiten, al educador de párvulos y niños y niñas, introducir un tema, desarrollarlo, modificarlo y concluirlo. El requerimiento de relacionar el tópico conlleva, a su vez, muchas otras características. Por una parte, la disponibilidad de explicitar el cambio de tópico o de estrategias para diversificarlo; así como también otras fórmulas que sirven para retomarlo o terminarlo.

c) Modalidad: es el tipo de comunicación que se utiliza en un discurso conversacional, esta puede ser verbal y no verbal.

\section{Resultados}

\section{El discurso conversacional en la observación de aula}

Las 16 educadoras de párvulos que participaron del estudio trabajan en La Junta Nacional de Jardines Infantiles, con un mínimo de experiencia de un año, y un máximo de treinta y un años de ejercicio profesional. En su gran mayoría estudiaron en universidades privadas (63\%), un $31 \%$ del total en universidades del Consejo de Rectores, y un $6 \%$ en institutos profesionales. El 50\% de ellas tienen el grado académico de Licenciada en Educación.

A continuación se analizaran cada una de las competencias lingüísticas especificadas anteriormente, según la frecuencia total en que se presentaron en la investigación.

a) Estructura: la información obtenida, luego de la aplicación de la pauta de observación a las 16 educadoras de párvulos, reveló que, en el inicio, se alcanzó un porcentaje de logro muy superior, pues un 94\% incorpora al niño a la conversación mediante una introducción verbal, solamente el $6 \%$ no lo hace.

En cuanto a los resultados obtenidos en el desarrollo mediante manejo de turno, la aplicación de la pauta reveló que el 54\% de las educadoras de párvulo son capaces de manejar la toma de turno. En cambio, el $46 \%$ restante presentan descendida la habilidad de mediadores eficientes, ya que fueron incapaces para controlar a los niños y niñas en el asumir o ceder los roles de hablante/oyente activos.

Respecto a los resultados obtenidos sobre el cierre de la conversación, la aplicación de la pauta evidenció que las educadoras de párvulos, en un alto porcentaje (75\%) finalizan la interacción conversacional verbalizando el término de esta, mientras que solo el $25 \%$ de los docentes no lo realiza.

b) Contenido: acerca de los resultados alcanzados en la evaluación del trabajo en el contenido, la aplicación de la pauta informó que las 16 educadoras de párvulos que participaron de este estudio alcanzaron un porcentaje de logro alto, ya que el $74 \%$ de ellas son capaces de 
URL: http://www.una.ac.cr/educare

CORREO: educare@una.cr

manejar el tópico. Es decir, las educadoras evaluadas tienen una serie de habilidades específicas que les permite introducir un tema, desarrollarlo, modificarlo y concluirlo. Por otra parte, el $26 \%$ restante tiene descendida estas habilidades, las cuales le permiten mantener el tópico de una conversación.

c) Modalidad: la aplicación de la pauta reveló que un $67 \%$ de las educadoras de párvulos entrega las instrucciones en forma exclamativa, interrogativa e imperativa, según corresponda; utilizan vocabulario conocido por los niños y niñas; especifican la información del tema de la conversación, y utilizan diferentes estilos de voz. En cambio, el 33\% restante presenta dificultades para utilizar una modalidad verbal adecuada, lo cual limita claramente un discurso conversacional.

En cuanto a la modalidad no verbal, los resultados obtenidos de la pauta de observación que se les aplicó a las educadoras de párvulos dan a conocer que el 59\% de ellos emplea medios que complementan los mensajes verbales como expresiones faciales, gestos corporales y distancias espaciales. El $41 \%$ restante no incorpora su cuerpo como herramienta de comunicación.

\section{Análisis de las competencias lingüísticas en el discurso conversacional}

\section{a) Estructura}

Los análisis relativos a la dimensión "estructura" en el desarrollo mediante manejo de turno, mostraron que la mayoría de las educadoras (un 94\%) cede el turno y deja el rol de emisor al niño. En cambio, el 6\% realiza un monólogo más que un discurso conversacional. Asimismo, respecto a si las educadoras interrumpen al niño cuando está de emisor, un $56 \%$ de ellos lo hace frecuentemente; mientras que un 44\% evita hacerlo, utilizando diferentes herramientas, como reglamentar la toma de turno, hacer silencio cuando alguien está hablando, dar la palabra a varios niños y niñas, entre otras. Además, se evidenció que las educadoras de párvulos también tienen dificultades -un 69\% de ellos- para evitar la sobreposición de turno cuando el niño esta de emisor.

Respecto a que si las educadoras dan el rol de emisor a varios niños respetando turno, un $38 \%$ de los evaluados lo realiza. En cambio, el $62 \%$ de las restantes cede el turno a algunos niños, los más participativos, o bien, interrumpe al niño que está de emisor (no dejando que termine su intervención conversacional). Por otro lado, un $56 \%$ de los docentes no espera que el niño ocupe su tiempo para asumir su turno, dándole la palabra a otro niño o interrumpiéndolo. Tan solo el $44 \%$ de los educadores evaluados respeta la latencia.

En cuanto a los resultados del indicador relativo a la minimización de preguntas y maximización de comentarios, la investigación muestra que un $81 \%$ de los docentes realiza un discurso conversacional dirigido hacia la pregunta, sobre todo cuando se les cede el turno a los niños y niñas. Solo el 19\% es capaz de seguir un discurso argumentativo. 
URL: http://www.una.ac.cr/educare CORREO: educare@una.cr

\section{b) Contenido}

La conversación es un suceso colaborativo, donde el tópico se debe dar en forma participativa. Para ello, debe haber coherencia en la conversación y se debe dar en forma estable. Al analizar los datos de la investigación, las educadoras de párvulos participantes entregaron la información específica de la actividad en un $100 \%$. Esto evidencia que, en general, realizan una conversación con un significado común.

Los resultados permiten conocer que el $62 \%$ de ellas no identifican las alteraciones que se van produciendo en la normal fluidez del discurso, mientras que hay un $38 \%$ capaz de reconocerla.

Finalmente, en lo que respecta al conocimiento por parte de las docentes respecto a los quiebres que se producen en la conversación, el análisis de la pauta muestra que un $75 \%$ de ellas no lo hace. Tan solo un $25 \%$ de las educadoras de párvulos plantea diferentes estrategias metodológicas para restaurar los quiebres que se producen en el discurso conversacional.

\section{c) Modalidad}

Finalmente, y respecto a la modalidad verbal, las educadoras de párvulos que participaron en la investigación especifican la información sobre el tema de la conversación en un 94\%, mientras que solo el $6 \%$ tiene problemas para establecer el discurso conversacional centrado en el tema.

Al analizar a los educadores de párvulos en la utilización de los estilos de voz que permiten mantener la atención de los niños y niñas en el discurso conversacional, la investigación demuestra que el $62 \%$ de ellos no emplea distintos estilos de voz, manteniendo una voz pareja. En cambio, el 38\% restante puede usar esta herramienta.

En el análisis del discurso conversacional en la modalidad no verbal, los datos obtenidos en la evaluación de la pauta revelan que la mayoría de las docentes (en un 94\%) miran a los niños y niñas mientras hablan, y que solo un $6 \%$ del profesorado evita hacerlo. Por otra parte, el indicador relativo a la mantención de un acercamiento adecuado por parte de las educadoras con los niños y niñas, la investigación permite conocer que un $69 \%$ de ellas está distantes mientras están conversando. El 31\% restante permanecen cercanas, interactuando con los niños y niñas.

Por último, sobre los movimientos corporales que las docentes deben realizar durante la conversación, la investigación plantea que el $56 \%$ del profesorado se mantiene sentado o parado en el mismo lugar, mientras que el $44 \%$ se moviliza por sala interactuando con los niños y niñas. 
URL: http://www.una.ac.cr/educare

CORREO: educare@una.cr

\section{Comportamientos lingüísticos de los educadores de párvulos}

A continuación se presenta el análisis de los comportamientos lingüísticos de las educadoras de párvulos. Es importante señalar que la aplicación de la pauta se realizó después de la observación del discurso conversacional con los niños y niñas, mientras estaban trabajando en una experiencia de aprendizaje (a través de un eje centralizador).

En cuanto a su estructura, la mayoría de las educadoras que participaron de esta investigación realizaron una instrucción verbal para iniciar la conversación, y la finalizaron verbalizando el término de esta.

De acuerdo con el análisis del desarrollo mediante manejo de turno, la mayoría de las educadoras de párvulos pueden mantener un discurso conversacional conectado con los niños y niñas. Según los resultados obtenidos, el $77 \%$ de ellos logran tener una conversación colaborativa, ceden su turno oportunamente, realizan pausa cuando entregan una nueva información y pueden regular a los niños y niñas cuando se salen del tema de la conversación. El $23 \%$ restante no tienen las competencias que les permiten realizar un discurso conversacional coordinado.

La evaluación de la pauta demuestra que el comportamiento lingüístico con respecto al contenido mediante el manejo de tópico, un $84 \%$ de las educadoras tiene las habilidades específicas que le permiten realizar un discurso conversacional coherente y cohesivo con los niños y niñas. Tan solo un $16 \%$ tiene disminuidas estas habilidades.

En lo que respecta a los comportamientos lingüísticos en la modalidad verbal, el análisis realizado a la pauta que aplicó demuestra que en un alto porcentaje (91\% de las docentes) realiza un discurso conversacional con un vocabulario conocido por los niños y niñas y entrega información específica sobre el tema de la conversación, mientras que tan solo el 9\% no puede trasmitir la información deseada.

\section{Conclusiones}

Por medio de esta investigación se pretendió dar a conocer las competencias lingüísticas de las educadoras estudiadas. Gracias a los resultados obtenidos y el análisis cuantitativo ha sido posible una aproximación a procesos tan complejos como la construcción del discurso y de los conocimientos que los profesionales de la educación tienen en contextos educativos. Los resultados obtenidos permitieron explorar e intentar comprender los componentes lingüísticos, los niveles de dominios y las dificultades que presentan el personal docente en el discurso conversacional al momento del aprendizaje de los niños y niñas.

Por medio de este estudio se han aportado datos relevantes para la comprensión del rol de mediador eficiente que deben cumplir quienes educan párvulos. Para ello se analizaron las competencias lingüísticas del discurso conversacional de carácter profesional como estructura, contenido y modalidad, por medio de una pauta de observación. Estos datos pueden obtenerse con una orientación en la mejora de la calidad de la enseñanza, porque proporcionan a la 
institución educativa información sobre cómo la intervención discursiva tiene unos efectos y unas funciones determinadas, y sobre la relación de estas funciones con la práctica pedagógica de docentes y los posibles resultados del aprendizaje en el lenguaje oral de los niños y niñas.

Por otro lado, el análisis de los resultados proporciona información valiosa respecto a la formación inicial y continua del cuerpo docente en el país. En este contexto, los educadores de párvulos -al reconocer los recursos que utilizan en su discurso- pueden analizar de un modo sistemático sus propias producciones, reflexionando en su práctica pedagógica. Para Cubero et al. (2008), esto traería, necesariamente, una mejora de sus habilidades comunicativas y de su comprensión de los propios procesos de enseñanza y aprendizaje. Al hacer consciente el discurso conversacional que utiliza, el personal docente podrá ser capaz de pensar en los tipos de conocimientos que va construyendo en los niños y niñas.

Ahora bien, las educadoras evaluadas tienen dificultades para organizar en los párvulos el manejo de turno provocando la sobreposición. Esto conlleva al quiebre de la comunicación, afecta la fluidez de la interacción y presenta enunciados incompletos, ambiguos, ininteligibles, entre otros. Para ello el personal docente debe ser capaz de reconocer la presencia de este quiebre y luego solucionarlo con las diversas estrategias de reparación (Martínez, 1999).

Por otro lado, las educadoras deben mejorar la habilidad para dotar de intencionalidad educativas sus discursos, como a su vez, mantener la comunicación por medio de los factores no verbales (movimientos y postura; manejo del espacio, gestos, prosodia, entre otros. El aprendizaje del habla, lectura y escritura se potencia, según Hohmann y Weikart (1999), por la necesidad de los niños y niñas de ser escuchados, que se les respondan sus inquietudes, puedan comunicar sentimientos, experiencias y deseos.

Desde estos antecedentes, las educadoras de párvulos podrán mejorar sus prácticas pedagógicas al hacer consientes sus dificultades en la conversación que realizan diariamente con los niños y niñas, para desarrollar el lenguaje oral en ellos, cumpliendo con su rol de mediadoras eficientes.

\section{Referencias}

Acosta, V. y Moreno, A. M. (1999). Dificultades del lenguaje en ambientes educativos: Del retraso al trastorno específico del lenguaje. Barcelona: Masson.

Bruner, J. (1998). Desarrollo cognitivo y educación. Selección de textos por Jesús Palacios (3a ed.). Madrid: Morata.

Cubero R., Cubero M., Santamaría A., de la Mata, M. L., Ignacio, C. M. y Prados M. (mayo-agosto, 2008). La educación a través de su discurso. Prácticas educativas y construcción discursiva del conocimiento en el aula. Revista de educación, 346, 71-104. Recuperado de http:// www.revistaeducacion.mec.es/re346/re346 03.pdf 
URL: http://www.una.ac.cr/educare

CORREO: educare@una.cr

Dale, P. (2003). Desarrollo del lenguaje. Un enfoque psicolingüístico (9a reimp.). México D. F.: Trillas.

Echeverría, R. (1997). Ontología del lenguaje (4ª ed.). Santiago: Paidós.

Feuerstein, R. (1999). The Theory of Structural Cognitive Modifiability [La teoría de modificabilidad estructural cognitiva]. En B. Presseisen (Ed.), Learning and Thinking Styles: Classroom Interaction [Estilos de aprendizaje y pensamiento: Interacción en el aula]. Washington, DC: NEA Professional Library, National Education Association.

Freire, P. (1973). ¿Extensión o comunicación? La concientización en el medio rural. Montevideo: Siglo XXI Editores.

Gutiérrez, A. y Montes, R. (2004). La importancia de la lectura y su problemática en el contexto educativo universitario. El caso de la Universidad Juárez Autónoma de Tabasco (México). Revista Iberoamericana de Educación. Recuperado de http://www.rieoei.org/ deloslectores/632Gutierrez.PDF

Hohmann, M. y Weikart, D. P. (1999). La educación de los niños pequeños en acción. Manual para los profesionales de la educación infantil. México, D. F.: Trillas.

Martínez, L. (1999). El discurso conversacional conceptos y componentes. (Apuntes de clase). Escuela de Fonoaudiología, Postgrado de la Facultad de Medicina de la Universidad de Chile.

Ministerio de Educación (MINEDUC). (2001). Bases curriculares de la educación parvularia. Santiago: Autor. Recuperado de http://www.oei.es/inicial/curriculum/bases curriculares chile.pdf

Pavez, M. M., Coloma, C. J., González, P., Palma, S. y Reinoso, C. (1999). El discurso narrativo en niños con TEL. Revista Chilena de Fonoaudiología, 1(2), 17-32.

Peralta, M. V. (1996). El currículo en el jardín infantil. Un análisis crítico ( $3^{\mathrm{a}}$ ed.). Santiago: Editorial Andrés Bello.

\section{Cómo citar este artículo en APA:}

Pérez, S. R. (enero-abril, 2014). Competencias lingüísticas de docentes de párvulos. Un análisis del discurso conversacional de profesionales de la Junta Nacional de Jardines Infantiles. Revista Electrónica Educare, 18(1), 177-192. Recuperado de http://www.revistas.una.ac.cr/index.php/EDUCARE/issue/current

Nota: Para citar este artículo en otros sistemas puede consultar el hipervínculo "Como citar el artículo" en la barra derecha de nuestro sitio web:

http://www.revistas.una.ac.cr/index.php/EDUCARE/index 